\title{
Prevalence of serological markers and risk factors for bloodborne pathogens in Salvador, Bahia state, Brazil
}

\author{
S. B. MATOS, A. L. S. R. JESUS, K. C. M. C. PEDROZA, H. R. S. SODRE, \\ T. L. H. FERREIRA AND F. W. M. LIMA* \\ Immunology Service of Infectious Diseases (ISID), Faculty of Pharmacy, Federal University of \\ Bahia state, Brazil
}

Received 11 August 2011; Final revision 8 February 2012; Accepted 19 February 2012; first published online 15 March 2012

\section{SUMMARY}

This study aimed to determine the prevalence of serological markers for HIV-1/2, HBV, HCV, Treponema cruzi and T. pallidum infections. The association of these infections with risk factors in a population from Salvador, Bahia, Brazil was also analysed. Of the 780 enrolled individuals, $545(70 \%)$ were female and $235(30 \%)$ were male. Seroprevalence of $0 \cdot 8 \%(6 / 702), 1 \cdot 3 \%(9 / 678)$, $1 \cdot 5 \%$ (10/684), $3 \cdot 5 \%$ (23/663) and $11 \cdot 5 \%$ (77/668) for HIV-1/2, HBV, HCV, T. cruzi and $T$. pallidum infections, respectively, was observed. The seroprevalence of $T$. pallidum was higher in males $20 \%(43 / 210)$ than in females $7 \%(34 / 458)(P<0 \cdot 01)$. An association between age and seroprevalence for T. cruzi $(P=0 \cdot 02)$ and T. pallidum $(P<0 \cdot 01)$ was observed. HBsAg was associated with having tattoos $(3 / 37 \mathrm{vs} .6 / 623, P=0.01)$ and not having a steady sexual partner (5/141 vs. 4/473, $P=0.04)$, while anti-HIV-1/2 was associated with having tattoos $(2 / 39$ vs. 4/647, $P=0 \cdot 04)$; however, larger studies are needed to categorically state the relationship of these risk factors with infectious agents. The prevalence of serological markers for HIV-1/2, HBV, HCV and T. cruzi was consistent with other studies.

Key words: Chagas disease, hepatitis, infectious diseases, syphilis, seroprevalence.

\section{INTRODUCTION}

Infectious diseases are among the leading causes of morbidity and mortality in healthcare institutions throughout the world and are considered a major public health problem [1]. HIV-1/2, hepatitis B virus (HBV), hepatitis C virus (HCV), Treponema cruzi and T. pallidum are infectious agents that mainly affect residents of underdeveloped or developing countries

\footnotetext{
* Author for correspondence: Dr F. W. M. Lima, Immunology Service of Infectious Diseases-ISID, Faculty of Pharmacy, Federal University of Bahia state, Rua Barão de Geremoabo, no. 147, Ondina, CEP 40170-115, Salvador, BA, Brazil. (Email:mlima@ufba.br)
}

[1-3]. Modes of transmission of infectious agents include vertical transmission from mothers to infants, sexual contact (except for T. cruzi), and exposure to blood and/or transfusion of blood products, sharing sharp objects and undergoing body piercing [4].

In 2009, the overall number of individuals infected with HIV was estimated to be 33 million [5]. In Brazil, from 1980 to June 2010, there were about 0.6 million cases of AIDS reported. There were 17886 cases reported in Bahia, ranking 8th in the Brazilian ranking of notifications in that referral period [6]. The World Health Organization (WHO) estimates that there are 350 million people worldwide with chronic HBV infection and 130 million people infected with 
hepatitis $\mathrm{C}$, most of whom have chronic $\mathrm{HCV}$ infection $[7,8]$. Sexually transmitted disease (STD) statistics show that there were 11 million new cases of syphilis worldwide in 2005 [9]. This infection affects about one million pregnant women per year, causing serious problems ranging from congenital syphilis to spontaneous abortion [10]. With respect to Chagas disease, it is believed that there are between 12 and 14 million individuals infected with $T$. cruzi in Latin America, and more than 60 million people are at risk of transmission in endemic areas [11].

This study aimed to determine the prevalence of serological markers for HIV-1/2, HBV, HCV, $T$. cruzi and T. pallidum in the population assisted by the Family Health Programme (FHP) in neighbourhoods of the city of Salvador, Bahia. The association of seropositivity rate with risk factors for such pathogens was also evaluated here.

\section{METHODS}

\section{Population and study design}

The studied population was informed of the research objectives and all persons who signed the informed consent were included. Thirty-two persons refused to participate. We obtained a blood sample from 780 individuals. Bloods samples were collected at a FHP healthcare unit in five major areas of the city of Salvador, Bahia.

For this cross-sectional study, secondary data were obtained through a questionnaire enquiring about potential risk factors for infection by HIV-1/2, HBV, HCV, T. cruzi and T. pallidum, including condom use, steady sexual partner, use of own manicure or pedicure kit, prior haemodialysis procedures, tattooing, piercing and history of blood transfusion. The participants completed the questionnaire alone in a separate room. Each subject was identified by a number control and the confidentiality of informations was guaranteed.

We collected $5 \mathrm{ml}$ blood in a vacuum system, using a test tube without anticoagulant or separating gel (BD Vacutainer ${ }^{\circledR} \mathrm{SS}^{\mathrm{TT}}$, USA). Biological samples were packed correctly and sent to the Immunology Service of Infectious Diseases (ISID) at the Faculty of Pharmacy, Federal University of Bahia (UFBA), where serological tests were performed.

The results of the immunoassays were sent to all FHP healthcare units, according to the origin of the biological material, as agreed previously with the participants. Thus, the participants could receive their results. This research protocol was approved by the Ethics Committee of Climério de Oliveira Maternity at UFBA.

\section{Serological tests}

The samples were subjected to serological tests for detection of markers of HIV-1/2 (Genscreen ${ }^{\text {TM }}$ HIV-1/2, v. 2, Bio-Rad, France), HBV (HBsAg Monolisa ${ }^{\mathrm{TM}}$ Ultra, Bio-Rad), HCV (HCV Ab, Radim, Italy), T. pallidum (Syphilis Screening Recombinant, Radim) and T. cruzi (ELISA Recombinant Chagatest, v. 3.0; Wiener, Argentina). The tests were performed using the automated system ALISEI (Radim), according to the manufacturer's protocol. The markers of HIV-1/2 and T. cruzi detected by ELISA were confirmed with an immunofluorescence assay (IFAHIV-1, Bio-Manguinhos, Brazil and Immuno-Con Chagas, WAMA Diagnostica, Brazil). Reactive samples for HBsAg, anti-HCV or anti-T. pallidum were confirmed in duplicate.

\section{Statistical analysis}

Statistical analysis was performed using SPSS v. 9.0 for Windows (SPSS Inc., USA) and GraphPad InStat (GraphPad Software Inc., USA). Categorical data were analysed with Fisher's exact test or $\chi^{2}$ test, accepting statistical significance as $P<0 \cdot 05$, with a twotailed analysis. The association between infections and the study variables was measured by unadjusted odds ratios (OR) at intervals of $95 \%$.

\section{RESULTS}

The present study included 780 individuals. Of these, $545(70 \%)$ were female (mean age $43 \cdot 2$, median age $44 \cdot 0$, S.D. $=14 \cdot 7, \min -\max 0-82$ years $)$ and $235(30 \%)$ were male (mean age $45 \cdot 8$, median age $47 \cdot 0$, s.D. $=$ $16 \cdot 7$, min-max 4-84 years). Overall, the mean age of the study population was 44 years (median $44 \cdot 0$, S.D. $=15 \cdot 4$, $\min -\max 0-84$ ).

Figure 1 shows the total seroprevalence found and the seroprevalence stratified by gender. The observed seroprevalence was $0.8 \%(6 / 702), 1 \cdot 3 \% \quad(9 / 678)$, $1 \cdot 5 \%(10 / 684), 3 \cdot 5 \%(23 / 665)$ and $11 \cdot 5 \%(77 / 668)$ for infections with HIV-1/2, HBV, HCV, T. cruzi and T. pallidum, respectively. Male subjects had a higher seroprevalence of $T$. pallidum $(20 \%, 43 / 210)$ than females $(7 \%, 34 / 458)(P<0 \cdot 01)$. 


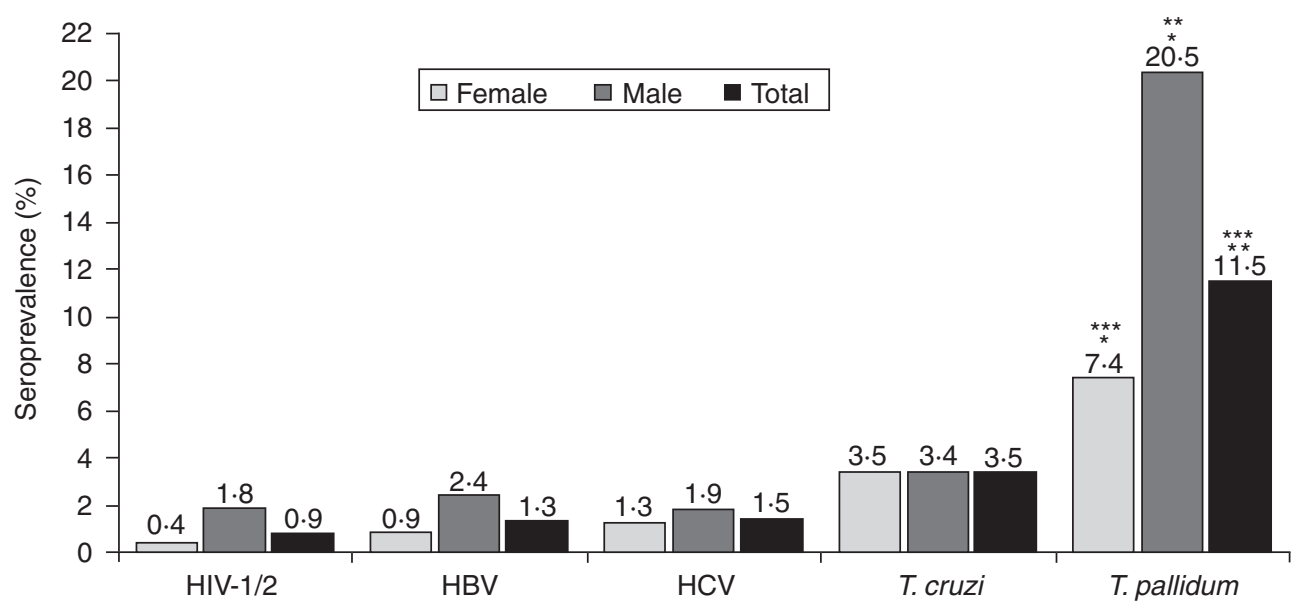

Fig. 1. Seroprevalence total stratified by gender. Data in absolute numbers for female, male and total, respectively: HIV-1/2 (2/485, 4/217, 6/702); HBV (4/466, 5/212, 9/678); HCV (6/471, 4/213, 10/684); Treponema cruzi (16/457, 7/208, 23/665); T. pallidum (34/458, 43/210, 77/668) (*P<0.01, ** $P<0 \cdot 01$, *** $P=0 \cdot 02)$.

Figure 2 shows the seroprevalence according to age group. Increasing prevalence was directly proportional to age in markers for infection by $T$. pallidum $(P<0 \cdot 01)$ and $T$. cruzi $(P=0 \cdot 02)$. No individuals aged $0-15$ years were positive for these serological markers.

Table 1 shows the seroprevalence of infections according to possible risk factors. There was a statistical association between positive serology for $\mathrm{HBs} A g$ and having tattoos $(3 / 37$ vs. $6 / 623, P=0 \cdot 01)$ and not having a steady sexual partner $(5 / 141 \mathrm{vs.} 4 / 473, P=0 \cdot 04)$. There was also an association between serological reactivity to HIV-1/2 and having tattoos (2/39 vs. 4/647, $P=0 \cdot 04)$.

\section{DISCUSSION}

Infectious diseases represent an increasingly important cause of human morbidity and mortality throughout the world, especially in underdeveloped or developing countries, where it is more challenging to diagnose and treat infections [12-14]. The FHP is an initiative arising from the need to expand healthcare and focuses on preventive measures and establishing links and co-responsibility between health professionals and the population [15]. The locations of the FHP are reference points for health activities in the neighbourhoods where the population has access to primary healthcare services [16].

Of the 780 individuals who participated in this study, $70 \%$ were female and $30 \%$ were male. The greater female participation is probably due to the fact that women are more attentive to healthcare issues than men and in general receive more frequent health services than men $[17,18]$.

The seroprevalence rates found in this study were $0.8 \%$ (HIV-1/2) $1.3 \%$ (HBV), $1.5 \%$ (HCV), $3.5 \%$ (T. cruzi) and $11.5 \%$ (T. pallidum) (Fig. 1). The only difference between the genders was with respect to infection with T. pallidum $(P<0 \cdot 01)$ (Fig. 1).

Several Brazilian studies have measured the prevalence of $T$. pallidum as ranging from 0.5 to $8.0 \%$ [19-24]. Miranda and colleagues [19] studied a total of 1380 young women (average age 23 years) in the city of Vitoria (Espírito Santo); they found a syphilis seroprevalence in these women of $1.2 \%$ [19]. Bartlett and colleagues [20] reported $3 \cdot 2 \%$ seropositivity for T. pallidum in 282 Indians of the Brazilian Amazon, and Ribeiro and colleagues [21] found $5.7 \%$ seroprevalence of syphilis in a municipal hospital in Duque de Caxias (Rio de Janeiro), where 1087 serum samples were tested.

Notably, most studies of the seroprevalence of syphilis are performed using the Venereal Disease Research Laboratory (VDRL) test, a non-treponemal test that has good correlation with active syphilis. However, in this study, we used an ELISA-type immunoassay for detection of total anti- $T$. pallidum antibodies which does not discriminate between active or past infection. On the other hand, some papers discuss the possibility of false-positives in treponemal tests. All T. pallidum subspecies are morphologically identical and cross-react to the same serological tests. Unexplained reactive serological results may occur, particularly in elderly patients. Some false-positive reactions may be due to the failure of the sorbent used 


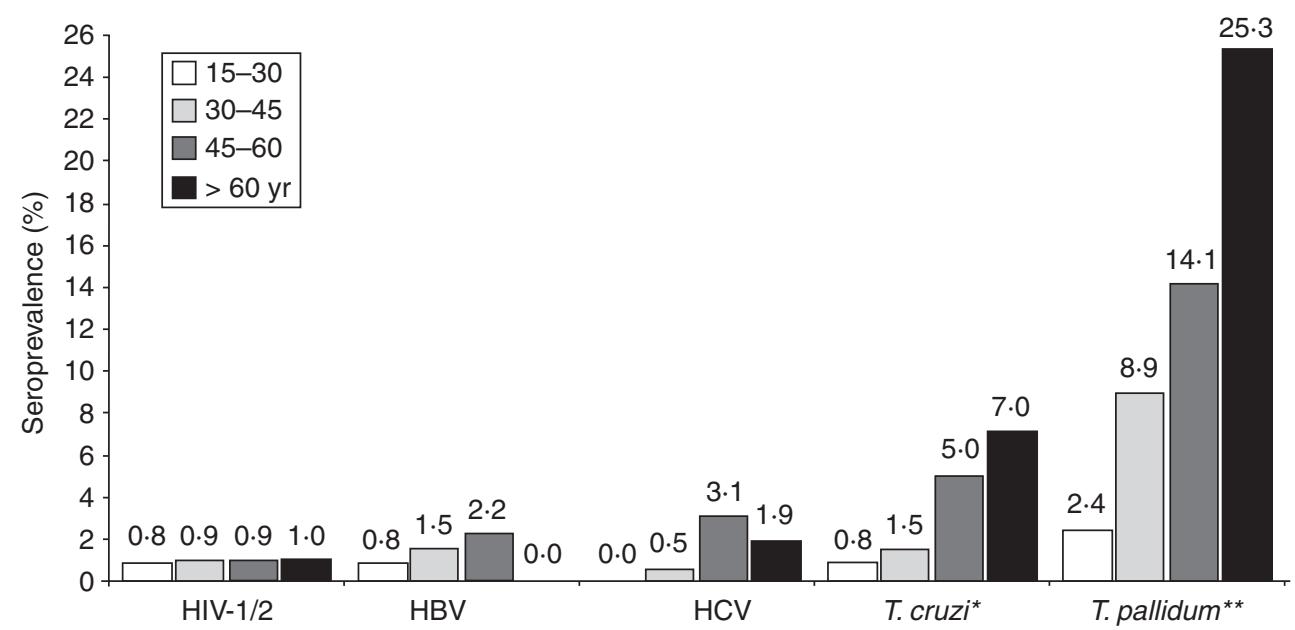

Fig. 2. Seroprevalence according to age group. Data in absolute numbers for age groups $15-30,30-45,45-60$, > 60 years, respectively: HIV-1/2 (1/132, 2/211, 2/232, 1/104); HBV (1/127, 3/203, 5/224, 0/103); HCV (0/129, 1/205, 7/226, 2/103); Treponema cruzi $(1 / 126,3 / 201,11 / 219,7 / 100) ;$. pallidum $(3 / 127,18 / 203,31 / 220,25 / 99)\left(* P=0 \cdot 02,{ }^{* *} P<0 \cdot 01\right)$.

in the tests to remove all cross-reacting group, genus, or family antibodies, e.g. in Lyme disease or yaws [25-27]. There are reports of the WHO from the 1950s that consider various areas of the Brazilian northeast, such as the southern part of Bahia state, endemic for yaws [28].

There are also two important factors that may have contributed to the high seroprevalence of antiT. pallidum found in our study: the social origin and age of the participants. Several studies indicate that STD are more prevalent in populations of lower socioeconomic status $[6,14,15]$. Our samples were obtained from individuals in different districts of Salvador, Bahia, where many people live in precarious socioeconomic conditions. The high seroprevalence of $T$. pallidum in the present study was observed in individuals aged $>30$ years (Fig. 2), confirming the findings of other researchers who suggest that STD rates are in direct proportion to increasing age of the individuals. The highest rates of STD in individuals aged $>30$ years may be due to the fact that these individuals have had more time to be exposed to the infectious agent and are more likely to be neglected by public health agencies that focus fewer health education efforts on individuals aged $>30$ years. Another factor may be the frequency of unprotected sex after age 30 years $[24,29]$. The higher seroprevalence of T. pallidum found in males $(P<0 \cdot 01)$ may be related to the factors mentioned above, or to unprotected extramarital sex (Fig. 1).

The seroprevalence of $\mathrm{HIV}-1 / 2, \mathrm{HBV}, \mathrm{HCV}$ and $T$. cruzi infection found in this study were similar to those found in other Brazilians cities (Fig. 1)
[6, 30, 31]. The Brazilian Health Department estimates that HIV infection ranges from $0.5 \%$ to $1 \%$ across Brazilian states [6]. Epidemiological studies on the prevalence of $\mathrm{HBV}$ or $\mathrm{HCV}$ infection are rare and usually conducted in specific populations. Globally, the prevalence of hepatitis $\mathrm{B}$ ranges from $0 \cdot 1 \%$ to $30 \%$ [31]. A prevalence study for HBsAg in São Paulo city detected reactivity in $1 \%$ of studied individuals [32]. Cities where the prevalence of HBsAg is $<2 \%$ are considered low-prevalence areas [33], which is the case for Salvador (Fig. 1).

Additional information on the background rates of hepatitis B infection (through anti-HBc testing) would be valuable to best characterize our patients; however, it was not possible due to internal difficulties in the logistics of purchasing the kits. HCV infection in the Brazilian population varies between $1 \%$ and $2 \%$ according to reports from various areas [33], although the national prevalence is not well established.

The seroprevalence of anti-T. cruzi antibodies observed in this study was $3.5 \%$ and was higher in individuals aged $>45$ years $(P=0.02)$ (Fig. 2). There was no difference between males and females $(3 \cdot 4 \%$ vs. $3.5 \%, P>0.05$ ) (Fig. 1). Silveira and colleagues [34] observed a prevalence of Chagas disease in $1.2 \%$ of 10667 blood donors in Rio de Janeiro, but a higher prevalence in individuals aged $>40$ years, possibly due to interruption of vector transmission of T. cruzi.

Some risk factors and behaviours may be associated with seroprevalence for various infectious diseases, including percutaneous exposure (parenteral) to contaminated needles or other instruments, multiple blood transfusions, intravenous drug 
Table 1. Risk factors for bloodborne Infections

\begin{tabular}{|c|c|c|c|c|c|c|c|c|c|c|c|c|c|c|c|c|c|c|c|c|c|c|c|c|c|c|c|c|c|c|}
\hline \multirow[b]{2}{*}{ Variables } & \multicolumn{2}{|c|}{ HIV $-1 / 2+$} & \multicolumn{2}{|c|}{ HIV-1/2- } & \multirow[b]{2}{*}{ OR } & \multirow[b]{2}{*}{$P$} & \multicolumn{2}{|c|}{$\mathrm{HBV}+$} & \multicolumn{2}{|c|}{$\mathrm{HBV}-$} & \multirow[b]{2}{*}{ OR } & \multirow[b]{2}{*}{$P$} & \multicolumn{2}{|c|}{$\mathrm{HCV}+$} & \multicolumn{2}{|c|}{$\mathrm{HCV}-$} & \multirow[b]{2}{*}{ OR } & \multirow[b]{2}{*}{$P$} & \multicolumn{2}{|c|}{$\mathrm{TC}+$} & \multicolumn{2}{|c|}{$\mathrm{TC}-$} & \multirow[b]{2}{*}{ OR } & \multirow[b]{2}{*}{$P$} & \multicolumn{2}{|c|}{$\mathrm{TP}+$} & \multicolumn{2}{|c|}{$\mathrm{TP}-$} & \multirow[b]{2}{*}{ OR } & \multirow[b]{2}{*}{$P$} \\
\hline & $n$ & $\%$ & $n$ & $\%$ & & & $n$ & $\%$ & $n$ & $\%$ & & & $n$ & $\%$ & $n$ & $\%$ & & & $n$ & $\%$ & $n$ & $\%$ & & & $n$ & $\%$ & $n$ & $\%$ & & \\
\hline \multicolumn{31}{|c|}{ Steady sexual partner } \\
\hline Yes & 5 & $1 \cdot 0$ & 491 & $99 \cdot 0$ & $1 \cdot 53$ & $1 \cdot 00$ & 4 & $0 \cdot 8$ & 473 & $99 \cdot 2$ & $0 \cdot 24$ & $0 \cdot 04$ & 6 & $1 \cdot 2$ & 476 & $98 \cdot 8$ & $0 \cdot 6$ & $0 \cdot 44$ & 11 & $2 \cdot 4$ & 455 & $97 \cdot 6$ & $0 \cdot 48$ & $0 \cdot 16$ & 54 & $11 \cdot 5$ & 416 & 88.5 & $0 \cdot 92$ & 0.77 \\
\hline No & 1 & $0 \cdot 7$ & 150 & $99 \cdot 3$ & & & 5 & $3 \cdot 4$ & 141 & $96 \cdot 6$ & & & 32 & $2 \cdot 0$ & 144 & $98 \cdot 0$ & & & 7 & $4 \cdot 8$ & 139 & $95 \cdot 2$ & & & 18 & $12 \cdot 4$ & 127 & $87 \cdot 6$ & & \\
\hline Own manic & & & & & & & & & & & & & & & & & & & & & & & & & & & & & & \\
\hline Yes & 2 & $0 \cdot 5$ & 367 & $99 \cdot 5$ & $0 \cdot 49$ & $0 \cdot 66$ & 6 & $1 \cdot 7$ & 355 & $98 \cdot 3$ & $1 \cdot 42$ & $0 \cdot 74$ & 8 & $2 \cdot 2$ & 354 & $97 \cdot 8$ & $2 \cdot 93$ & $0 \cdot 21$ & 15 & $4 \cdot 3$ & 337 & 95.7 & $2 \cdot 22$ & $0 \cdot 17$ & 39 & $11 \cdot 0$ & 313 & $89 \cdot 0$ & $0 \cdot 91$ & $0 \cdot 70$ \\
\hline No & 3 & $1 \cdot 1$ & 269 & $98 \cdot 9$ & & & 3 & $1 \cdot 2$ & 253 & $98 \cdot 8$ & & & 2 & $0 \cdot 8$ & 259 & $99 \cdot 2$ & & & 5 & $2 \cdot 0$ & 249 & $98 \cdot 0$ & & & 31 & $12 \cdot 0$ & 226 & $88 \cdot 0$ & & \\
\hline Prior haem & & & & & & & & & & & & & & & & & & & & & & & & & & & & & & \\
\hline Yes & 0 & $0 \cdot 0$ & 3 & $100 \cdot 0$ & $14 \cdot 6$ & $1 \cdot 00$ & 0 & $0 \cdot 0$ & & $100 \cdot 0$ & $9 \cdot 62$ & $1 \cdot 00$ & 0 & $0 \cdot 0$ & 3 & $100 \cdot 0$ & $8 \cdot 76$ & $1 \cdot 00$ & 0 & $0 \cdot 0$ & 3 & $100 \cdot 0$ & $3 \cdot 73$ & $1 \cdot 00$ & 0 & $0 \cdot 0$ & & $100 \cdot 0$ & $1 \cdot 06$ & $1 \cdot 00$ \\
\hline No & 6 & $0 \cdot 9$ & 664 & $99 \cdot 1$ & & & 9 & $1 \cdot 4$ & 639 & $98 \cdot 6$ & & & 10 & $1 \cdot 5$ & 643 & 98.5 & & & 23 & $3 \cdot 6$ & 613 & $96 \cdot 3$ & & & 75 & $11 \cdot 8$ & 563 & $88 \cdot 2$ & & \\
\hline Tattoos & & & & & & & & & & & & & & & & & & & & & & & & & & & & & & \\
\hline Yes & 2 & $4 \cdot 9$ & 39 & $95 \cdot 1$ & $8 \cdot 3$ & $0 \cdot 04$ & 3 & $7 \cdot 5$ & 37 & 92.5 & $8 \cdot 41$ & $0 \cdot 01$ & 12 & $2 \cdot 5$ & 39 & $97 \cdot 5$ & $1 \cdot 78$ & $0 \cdot 46$ & 0 & $0 \cdot 0$ & 39 & $100 \cdot 0$ & $0 \cdot 32$ & $0 \cdot 39$ & 5 & $12 \cdot 8$ & 34 & $87 \cdot 2$ & $1 \cdot 12$ & $0 \cdot 80$ \\
\hline No & 4 & $0 \cdot 6$ & 647 & $99 \cdot 4$ & & & 6 & $1 \cdot 0$ & 623 & $99 \cdot 0$ & & & 9 & $1 \cdot 4$ & 625 & $98 \cdot 6$ & & & 23 & $3 \cdot 7$ & 594 & $96 \cdot 3$ & & & 72 & $11 \cdot 6$ & 547 & $88 \cdot 4$ & & \\
\hline Piercing & & & & & & & & & & & & & & & & & & & & & & & & & & & & & & \\
\hline Yes & 0 & $0 \cdot 0$ & 19 & $100 \cdot 0$ & $2 \cdot 53$ & $1 \cdot 00$ & 0 & $0 \cdot 0$ & 19 & $100 \cdot 0$ & 1.67 & $1 \cdot 00$ & 0 & $0 \cdot 0$ & 19 & $100 \cdot 0$ & $1 \cdot 52$ & $1 \cdot 00$ & 0 & $0 \cdot 0$ & 18 & $100 \cdot 0$ & $0 \cdot 71$ & $1 \cdot 00$ & 1 & $5 \cdot 6$ & 17 & $94 \cdot 4$ & $0 \cdot 44$ & $0 \cdot 71$ \\
\hline No & 6 & $0 \cdot 9$ & 643 & $99 \cdot 1$ & & & 9 & $1 \cdot 4$ & 617 & $98 \cdot 6$ & & & 10 & $1 \cdot 6$ & 622 & $98 \cdot 4$ & & & 22 & $3 \cdot 6$ & 592 & $96 \cdot 4$ & & & 73 & $11 \cdot 8$ & 544 & $88 \cdot 2$ & & \\
\hline Prior blood & & & & & & & & & & & & & & & & & & & & & & & & & & & & & & \\
\hline Yes & 0 & $0 \cdot 0$ & 6 & $100 \cdot 0$ & $7 \cdot 99$ & $1 \cdot 00$ & 0 & $0 \cdot 0$ & 5 & $100 \cdot 0$ & 6.96 & $1 \cdot 00$ & 0 & $0 \cdot 0$ & 5 & $100 \cdot 0$ & $5 \cdot 67$ & $1 \cdot 00$ & 0 & $0 \cdot 0$ & 4 & $100 \cdot 0$ & $2 \cdot 95$ & $1 \cdot 00$ & 0 & $0 \cdot 0$ & & $100 \cdot 0$ & $0 \cdot 87$ & $1 \cdot 00$ \\
\hline No & 6 & $0 \cdot 9$ & 675 & $99 \cdot 1$ & & & 8 & $1 \cdot 2$ & 650 & $98 \cdot 8$ & & & 10 & $1 \cdot 5$ & 654 & 98.5 & & & 23 & $3 \cdot 6$ & 623 & $96 \cdot 4$ & & & 73 & $11 \cdot 2$ & 576 & $88 \cdot 8$ & & \\
\hline Condom & & & & & & & & & & & & & & & & & & & & & & & & & & & & & & \\
\hline Yes & 5 & $2 \cdot 3$ & 212 & $97 \cdot 7$ & $10 \cdot 3$ & 0.02 & 3 & $1 \cdot 4$ & 207 & $98 \cdot 6$ & $1 \cdot 00$ & $1 \cdot 00$ & 4 & 1.9 & 210 & $98 \cdot 1$ & 1.59 & $0 \cdot 49$ & 3 & $1 \cdot 4$ & 204 & $98 \cdot 6$ & $0 \cdot 34$ & 0.09 & 26 & $12 \cdot 4$ & 184 & $87 \cdot 6$ & $1 \cdot 08$ & 0.79 \\
\hline No & 1 & $0 \cdot 2$ & 437 & $99 \cdot 8$ & & & 6 & $1 \cdot 4$ & 415 & 98.6 & & & 5 & $1 \cdot 2$ & 418 & $98 \cdot 8$ & & & 17 & $4 \cdot 1$ & 396 & 95.9 & & & 48 & $11 \cdot 6$ & 365 & 88.4 & & \\
\hline
\end{tabular}

HBV, Hepatitis B virus; HCV, hepatitis c virus; TC, Treponema cruzi; TP, Treponema pallidum; OR, odds ratio.

Data collected in the questionnaire about previous hospitalization, use of daily medications and having lived in other cities in Bahia state were deleted from the table

When one value is zero, to make calculations possible, $0 \cdot 5$ was added to each value. 
use, sexual promiscuity, unprotected anal intercourse, body piercing, tattoos or dental procedures, or unsafe medical and surgical practices [12-14].

This study involved a questionnaire designed to evaluate risk factors for each tested infection (Table 1). A statistical association was observed between positive serology for HBsAg and tattoos (3/37 vs. $6 / 623, P=0.01)$ and not having a steady sexual partner (5/141 vs. 4/473, $P=0 \cdot 04)$. There was also an association between serological reactivity of $\mathrm{HIV}-1 / 2$ with tattoos $(2 / 39$ vs. $4 / 647, P=0 \cdot 04)$ (Table 1$)$, underscoring the importance of achieving better sanitation monitoring of establishments that perform tattoo placement in Salvador, Bahia.

It is worth emphasizing that $83 \cdot 3 \%(5 / 6)$ of individuals who were seropositive for HIV-1/2 reported using condoms during sexual relations (Fig. 1), thus besides the necessity for public health campaigns to emphasize the importance of using condoms during all sexual relations between seropositive or serodiscordant couples, it is also necessary to adopt continuous preventive actions to reduce the virus dissemination in general population $[35,36]$.

\section{CONCLUSION}

The prevalence of serological markers for HIV-1/2, HBV, HCV and T. cruzi in individuals assisted by the FHP in Salvador, Bahia is in agreement with other published data. The high seroprevalence of $T$. pallidum, especially in men aged $>45$ years, and the association between HIV-1/2 and HBV infection with having tattoos, should be carefully considered by competent public health authorities; however, larger studies are needed to categorically state the relationship of these risk factors with infectious agents. This investigation demonstrates both the local importance of thorough investigation of the various risk factors involved in infectious diseases and the need to conduct ongoing health education in the city of Salvador, Bahia.

\section{ACKNOWLEDGEMENTS}

The authors are grateful to the study participants and to Dr Daniel Lima de Moura, Dr Adriano Serva Matos Ferreira and Dr Maria Virgínia Avelar.

\section{DECLARATION OF INTEREST}

None.

\section{REFERENCES}

1. Ros CTD, Schimitt CS. Global epidemiology of sexually transmitted diseases. Asian Journal of Andrology 2008; 10: 110-114.

2. Ciorlia LAS, Zanetta DMT. Hepatitis C in health care professionals: prevalence and association with risk factors. Revista de Saúde Pública 2007; 41: 229-235.

3. Stramer SL. Current risks of transfusion-transmitted agents: a review. Archives of Pathology \& Laboratory Medicine 2008; 131: 702-707.

4. Ferreira AW, Ávila SLM. Laboratory Diagnosis of Main Infectious Diseases, 5th edn. Rio de Janeiro: Guanabara Koogan, 2001, pp. 443.

5. Joint United Nations Programme on HIV/AIDS (UNAIDS). UNAIDS Report on the global AIDS epidemic. Database (http://www.unaids.org/globalreport/ default.htm). Accessed 10 January 2011.

6. Brazilian Ministry of Health. SIDA/STD Epidemiological Bulletin. Brazil. Year VII, no. 01, 2010.

7. World Health Organization (WHO). Hepatitis B. Database (http://www.who.int/mediacentre/factsheets/ fs204/en/). Accessed 24 January 2011.

8. Fabiani FL. Epidemiology of hepatitis $\mathrm{C}$ virus infection. World Journal of Gastroenterology 2007; 13: 2436-2441.

9. Mabey D. Epidemiology of STIs: worldwide. Epidemiology and Sexual Behaviour. Medicine 2010; 38: 216-219.

10. Pónyai K, et al. Syphilis: today. Reviews in Medical Microbiology 2010; 21 : 84-95.

11. Dias JCP. Globalization, inequity and Chagas disease. Caderno de Saúde Pública 2007; 23: S13-S22.

12. Brazilian Ministry of Health. Brazil. Secretary of Health Surveillance. Infectious and Parasitic Diseases: Pocket Guide. Brasilia, 2005.

13. Dehne KL, Riedner G. Sexually transmitted infections among adolescents: the need for adequate health services. Reproductive Health Matters 2001; 9: 170-183.

14. Thomas DJ. Sexually transmitted viral infections: epidemiology and treatment. Journal of Obstetric, Gynecologic and Neonatal Nursing 2001; 30: 316-323.

15. Oliveira AKP, Borges DF. Family Health Program: effectiveness assessment based on user perception. Revista de Administração Pública 2008 ;42: 369-389.

16. Elias PE, et al. Primary health care: a comparison of PSF and UBS units per stratum of socially excluded users in the city of São Paulo. Revista Ciencia e Saúde Coletiva 2006; 11: 633-641.

17. Cherry DK, Woodwell DA. National ambulatory medical care survey: 2005 summary. Advance Data 2007; 328: $1-32$.

18. Pinheiro RS, et al. Gender, morbidity, access and utilization of health services in Brazil. Revista Ciência e Saúde Coletiva 2002; 7 : 687-707.

19. Miranda AE, et al. Prevalence of syphilis and HIV using rapid tests in pregnant women seen in public hospitals in Vitória, Espírito Santo. Revista da Sociedade Brasileira de Medicina Tropical 2008; 42: 386-391. 
20. Bartlett EC, et al. Expansion of HIV and syphilis into the Peruvian Amazon: a survey of four communities of an indigenous Amazonian ethnic group. International Journal of Infectious Diseases 2008; 12: 89-94.

21. Ribeiro AS, Souza FB, Pinto SS. Syphilis screening: incidence of positive results in the Duque de Caxias hospital, originating at the Center for Counseling and Testing for STDs and SIDA. NewsLab 2007; 82: 142-155.

22. Brito VOC, et al. HIV infection, hepatitis B and C and syphilis in homeless people, in the city of São Paulo, Brazil. Revista de Saúde Pública 2007; 41: 47-56.

23. Silva BSP, et al. Frequency of antibodies to the etiologic agents of acquired immunodeficiency syndrome, syphilis, hepatitis $\mathrm{B}$ and $\mathrm{C}$, and Chagas disease in rheumatology patients treated with anti tumor necrosis (tumor necrosis factor-TNF). Revista Brasileira de Reumatologia 2009; 49: 590-598.

24. Catalan-Soares BC, Almeida RTP, Carneiro-Proietti ABF. Prevalence of HIV-1/2, HTLV-I/II, hepatitis B virus (HBV), hepatitis $\mathrm{C}$ virus (HCV), Treponema pallidum and Trypanosoma cruzi among prison inmates at Manhuaçu, Minas Gerais State, Brazil. Revista da Sociedade Brasileira de Medicina Tropical 2000; 33: 27-30

25. Satter EK, Tokarz VA. Secondary yaws: an endemic treponemal infection. Pediatric Dermatology 2010; 24: 364-367.

26. Larsen AS, Steiner BM, Rudolph AH. Laboratory diagnosis and interpretation of tests for syphilis. Clinical Microbiology Reviews 1995; 8: 1-21.

27. Rinaldi A. Yaws: a second (and maybe last?) chance for eradication. PLoS Neglected Tropical Diseases 2008; 2: 1-6.
28. Aquino UM. Yaws in Brazil. Bulletin of the World Health Organization 1958; 18: 461-463.

29. Olivi M, Santana RG, Mathias TAF. Behavior, knowledge and perception of risks about sexually transmitted diseases in a group of people over 50 years old. Revista Latino-Americana de Enfermagem 2008; 16: 679-685.

30. Melo HMA, et al. Awareness about Aids among elderly males and young adults: a study of the perception of this disease. Revista Ciência e Saúde Coletiva. Database (http://www.cienciaesaudecoletiva.com.br/ artigos/artigo_int.php?id_artigo =5703). Accessed 1 February $201 \overline{1}$.

31. Toledo Jr. AC, et al. Seroprevalence of hepatitis B and $\mathrm{C}$ in Brazilian army conscripts in 2002. A crosssectional study. Brazilian Journal of Infectious Diseases 2005; 9: 374-383.

32. Focaccia R, et al. Viral hepatitis prevalence in Sao Paulo. In: Focaccia R, ed. Treatment of Viral Hepatitis Atheneu, São Paulo, 2003.

33. Ferreira CT, Silveira TR. Viral hepatitis: epidemiological and preventive aspects. Revista Brasileira de Epidemiologia 2004; 7 : 473-487.

34. Silveira HJ, et al. Trypanosoma cruzi prevalence and clinical forms in blood donor candidates in Brazil. Revista de Saúde Pública 2003; 37: 807-809.

35. Reis RK, Gir E. Vulnerability and prevention of sexual HIV transmission among HIV/AIDS serodiscordant couples. Revista da Escola de Enfermagem 2009; 43: 662-669.

36. Matos SB, et al. Information level, risk perception and HIV/AIDS socio-cultural aspects relation in young people of Itabuna, Northeast, Brazil. Internet Journal of Health 2009; (9)2. 